\title{
BIOINFORMATICS FOR UNDERGRADUATES OF LIFE SCIENCE COURSES
}

\author{
De Mesquita, J.F. ${ }^{1,2}$, Paiva, C.L.A. ${ }^{1}$
}

${ }^{1}$ Universidade Federal do Estado do Rio de Janeiro - Unidade de Genética e Biologia

Molecular, Rio de Janeiro, RJ, Brazil; ${ }^{2}$ Universidade Severino Sombra-CCS,

Vassouras, RJ, Brazil. e-mail: jfreire@biomol.net

In the recent years, Bioinformatics has emerged as an important research tool. The ability to mine large databases for relevant information has become essential for different life science fields. On the other hand, providing education in bioinformatics to undergraduates is challenging from this multidisciplinary perspective. Therefore, it is important to introduced undergraduate students to the available information and current methodologies in Bioinformatics. Here we report the results of a course using a computer-assisted and problem-based learning model. The syllabus was comprised of theoretical lectures covering different topics within bioinformatics and practical activities. For the latter, we developed a set of step-by-step tutorials based on case studies. The course was applied to undergraduate students of biological and biomedical courses. At the end of the course, the students were able to build up a step-by-step tutorial covering a bioinformatics issue.

Financial support: Esso Brasileira de Petróleo Limitada. 